\title{
STRUCTURE AND MAGNETIC PROPERTIES OF Nd-Fe-B ALLOYS WITH Cu ADDITIONS, OBTAINED BY MECHANICAL SYNTHESIS
}

\author{
Kirill PANOV, Igor SHCHETININ, Igor BORDYUZHIN, Vladimir MENUSHENKOV, \\ Irina DOROFIEVICH \\ National University of Science and Technology "MISiS" (NUST "MISiS"), Moscow, Russia, \\ ingvvar@gmail.com
}

https://doi.org/10.37904/metal.2020.3610

\begin{abstract}
In this work the phase transformations in Nd-Fe-B alloys with copper additives obtained by mechanochemical synthesis (MS) was studied. After MS process a partial decomposition of the $\mathrm{Nd}_{2} \mathrm{Fe}_{14} \mathrm{~B}$ crystalline phase into the amorphous phase and $\alpha-\mathrm{Fe}$ occurs with a maximum ratio of 20 and $8 \%$, respectively. According to SEM data, the particle size was $1 \mu \mathrm{m}$ with a substructure. The heat treatment of $\mathrm{Nd}-\mathrm{Fe}-\mathrm{B}$ alloys with $\mathrm{Cu}$ additives leads to crystallization of the amorphous phase and an increase in coercive force and residual magnetization. The maximum hysteresis properties were achieved for the sample with the addition of $0.4 \% \mathrm{Cu}: \mathrm{H}_{c}=376 \mathrm{kA}$ / $\mathrm{m}$ and $\sigma_{r}=65 \mathrm{~A} \cdot \mathrm{m}^{2} / \mathrm{kg}$. It was shown that an increase in coercive force is associated with the presence of a mechanism for pinning of domain walls.
\end{abstract}

Keywords: $\mathrm{Nd}-\mathrm{Fe}-\mathrm{B}$, mechanical synthesis, $\mathrm{XRD}$, magnetic properties, grain boundaries

\section{INTRODUCTION}

In recent times, hard magnetic materials have many applications in a variety of industries, including various engines, generators and also targeted drug delivery [1]. Industrial needs require a steady increase in the magnetic energy product $(B H)_{\max }$ and the production of permanent magnets as well [2]. The maximum energy product was achieved on the Nd-Dy-Fe-B system alloys obtained by powder metallurgy methods. However, due to the low natural resources and high cost of Dy, there is a significant demand for permanent magnets without Dy. In this regard, nanocrystalline or nanocomposite permanent magnets obtained by extreme methods (high-energy milling, intense plastic deformation, quenching from a liquid state, etc.) $[3,4]$ are of particular interest. In these systems, effects of exchange coupling, the formation of intergranular phases, which change the exchange interaction between grains and increase the coercivity, can be observed [5-9]. Many experimental and theoretical studies indicate a positive effect of $\mathrm{Cu}$ additives on the formation of intergranular phases [7], which leads to an increase of magnetic properties. However, almost all works in this area are devoted to studying the effect of $\mathrm{Cu}$ on magnets obtained by traditional methods of powder metallurgy. In this regard, the study of the structure formation and magnetic properties of nanocomposite alloys based on the $\mathrm{Nd}-\mathrm{Fe}-\mathrm{B}$ system with $\mathrm{Cu}$ additives obtained by mechanochemical synthesis is an urgent task.

\section{EXPERIMENTAL}

Alloy of the $\mathrm{Nd}-\mathrm{Fe}-\mathrm{B}$ system with a stoichiometric atomic composition $\mathrm{Nd}_{12} \mathrm{Fe}_{82} \mathrm{~B}_{6}$ was obtained from pure components $\mathrm{Nd}$, $\mathrm{Fe}$ and $\mathrm{Fe}-\mathrm{B}$ with a purity of no worse than $99.9 \%$ by vacuum induction melting in an amount of $1 \mathrm{~kg}$. After melting, the alloy was annealed (homogenised) in vacuum at a temperature $1100{ }^{\circ} \mathrm{C}$ for 40 hours. The Nd-Fe-B powder was obtained by crushing and grinding in a mortar and then mixed with $0-0.5 \%$ of $\mathrm{Cu}$ powder. The resulting mixture was subjected to mechanochemical synthesis (up to 2 hours). The 
mechanochemical synthesis was carried out in a high-energy ball mill "Activator $2 \mathrm{~S}$ " in an argon atmosphere (vial rotation speed: $800 \mathrm{rpm}$ ). Ball-to-powder ratio was 20:200. After mechanochemical synthesis the powders were subjected to the annealing at $560-620^{\circ} \mathrm{C}$ for 15 minutes in vacuum furnace. X-ray diffraction (XRD) analysis was performed on a Rigaku Ultima IV diffractometer using Co-Ka radiation. Spectrum analysis was performed using PDXL software (Rigaku). The quantitative analysis of the amorphous phase was performed according to the procedure described in [10]. The microstructure of the alloys was studied using a TESCAN VEGA 3 SBH electron microscope. The magnetic properties were measured on a PPMS VSM (Quantum Design) facility. Magnetic properties were measured on samples taking into account the demagnetizing factor.

\section{RESULTS AND DISCUSSION}

According to the results of XRD analysis after 2-hour milling a partial amorphization of the $\mathrm{Nd}_{2} \mathrm{Fe}_{14} \mathrm{~B}$ phase occurs with a small amount of $\alpha-\mathrm{Fe}$. The obtained XRD patterns for all samples are almost identical; therefore, it is not possible to draw fast conclusions about the effect of $\mathrm{Cu}$ additives on the amorphization kinetics and phase transformations after only a 2-hour mechanochemical synthesis. Typical XRD patterns of samples subjected to MS for 2 hours are shown in Figure 1. The results of the qualitative and quantitative XRD analysis are shown in Table 1.

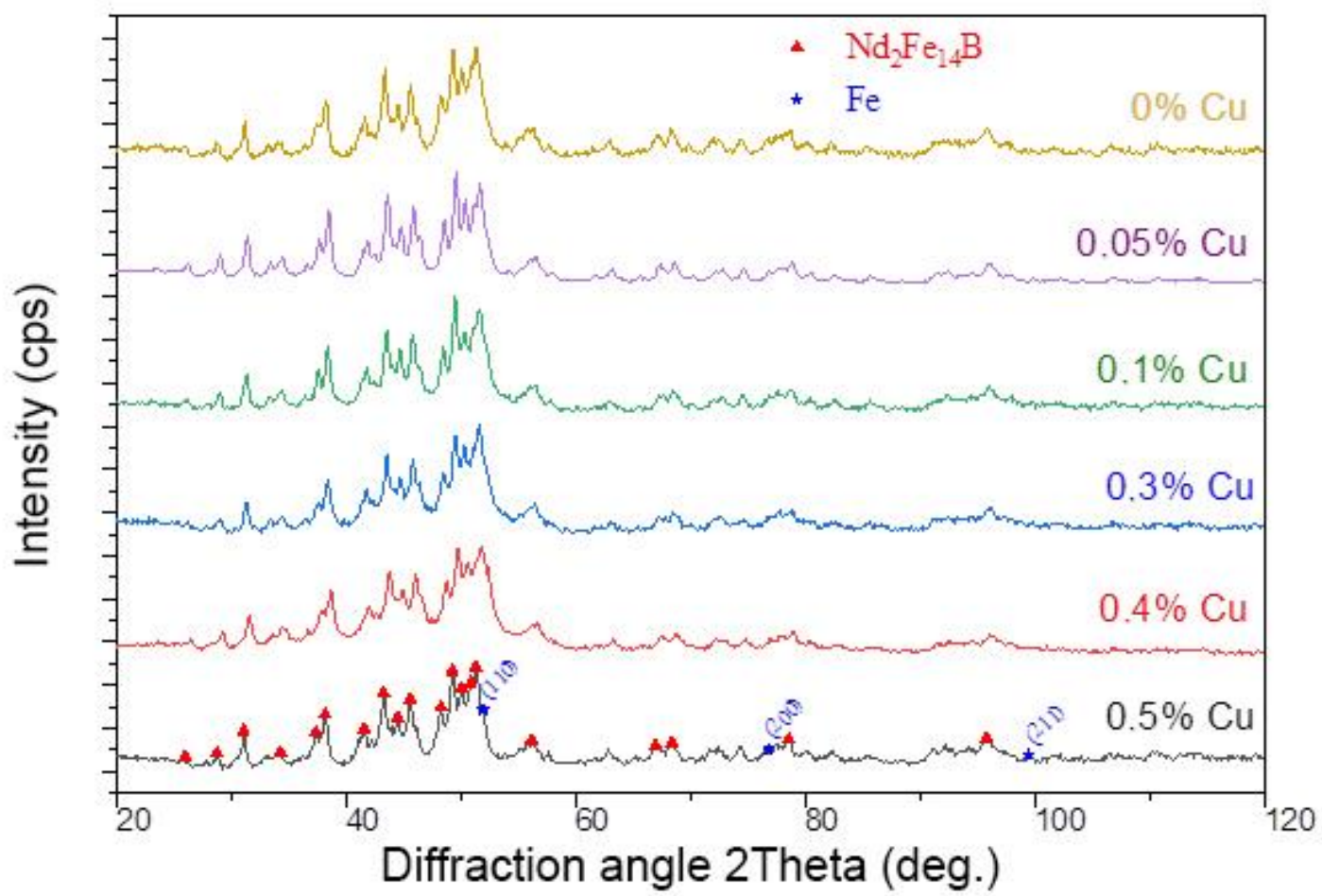

Figure 1 Typical XRD patterns of the Nd-Fe-B samples with $\mathrm{Cu}$ additives after 2 hours of mechanochemical synthesis

The results of a scanning electron microscopy (SEM) study of the Nd-Fe-B alloy with $0.05 \% \mathrm{Cu}$ are shown in Figure 2. It can be seen that the particle size after 2 hours of mechanochemical synthesis is $1-10 \mu \mathrm{m}$, but the particles have a substructure. According to $\mathrm{X}$-ray microanalysis, the chemical composition of the particles is comparable with the stoichiometry of the $\mathrm{Nd}_{2} \mathrm{Fe}_{14} \mathrm{~B}$ compound.

Figure 3 shows the XRD patterns of the Nd-Fe-B samples with $\mathrm{Cu}$ after annealing ( $600{ }^{\circ} \mathrm{C}$ for 15 minutes). Quantitative and qualitative phase analysis results are presented in Table 2.

According to the XRD results, it is evident that the main phase in the alloy is the crystalline phase $\mathrm{Nd}_{2} \mathrm{Fe}_{14} \mathrm{~B}$. In addition, about $5 \%$ of $\mathrm{Nd}_{2} \mathrm{O}_{3}$ oxide appears during $\mathrm{MS}$ and heat treatment, and nanocrystalline $\alpha-\mathrm{Fe}$ also 
appears. The lattice parameters vary insignificantly, which may indicate that $\mathrm{Cu}$ does not form solid solutions and does not dissolve in the lattice of the $\mathrm{Nd}_{2} \mathrm{Fe}_{14} \mathrm{~B}$ compound. XRD analysis failed to detect traces of the phases' formation between neodymium and copper. This may indicate that perhaps their content is insufficient for the sensitivity of the XRD method, or Cu has dissolved along the grain boundaries. An excessive Fe content indicates on this also. Its content exceeds the value that should have been released during the formation of $\mathrm{Nd}_{2} \mathrm{O}_{3}$ phase.

Table 1 The results of qualitative and quantitative XRD phase analysis of the samples with Cu additions after mechanochemical synthesis

\begin{tabular}{|c|c|c|c|c|c|}
\hline \multirow{2}{*}{ Sample } & \multicolumn{3}{|c|}{ Phase mass fraction (\%) } & \multicolumn{2}{|c|}{ Crystallite size (nm) } \\
\hline & $\mathrm{Nd}_{2} \mathrm{Fe}_{14} \mathrm{~B}$ & $\alpha-F e$ & Amorphous phase & $\mathrm{Nd}_{2} \mathrm{Fe}_{14} \mathrm{~B}$ & $\alpha-F e$ \\
\hline $\mathrm{Nd}_{2} \mathrm{Fe}_{14} \mathrm{~B}+0 \% \mathrm{Cu}$ & $77 \pm 3$ & $3 \pm 1$ & $20 \pm 3$ & $20 \pm 1$ & $15 \pm 1$ \\
\hline $\mathrm{Nd}_{2} \mathrm{Fe}_{14} \mathrm{~B}+0.05 \% \mathrm{Cu}$ & $78 \pm 3$ & $3 \pm 1$ & $19 \pm 3$ & $18 \pm 1$ & $15 \pm 1$ \\
\hline $\mathrm{Nd}_{2} \mathrm{Fe}_{14} \mathrm{~B}+0.1 \% \mathrm{Cu}$ & $78 \pm 3$ & $3 \pm 1$ & $18 \pm 3$ & $17 \pm 1$ & $15 \pm 1$ \\
\hline $\mathrm{Nd}_{2} \mathrm{Fe}_{14} \mathrm{~B}+0.3 \% \mathrm{Cu}$ & $78 \pm 3$ & $8 \pm 2$ & $20 \pm 3$ & $15 \pm 1$ & $14 \pm 1$ \\
\hline $\mathrm{Nd}_{2} \mathrm{Fe}_{14} \mathrm{~B}+0.4 \% \mathrm{Cu}$ & $78 \pm 3$ & $3 \pm 1$ & $19 \pm 3$ & $14 \pm 1$ & $15 \pm 1$ \\
\hline $\mathrm{Nd}_{2} \mathrm{Fe}_{14} \mathrm{~B}+0.5 \% \mathrm{Cu}$ & $78 \pm 3$ & $3 \pm 1$ & $20 \pm 3$ & $14 \pm 1$ & $15 \pm 1$ \\
\hline
\end{tabular}
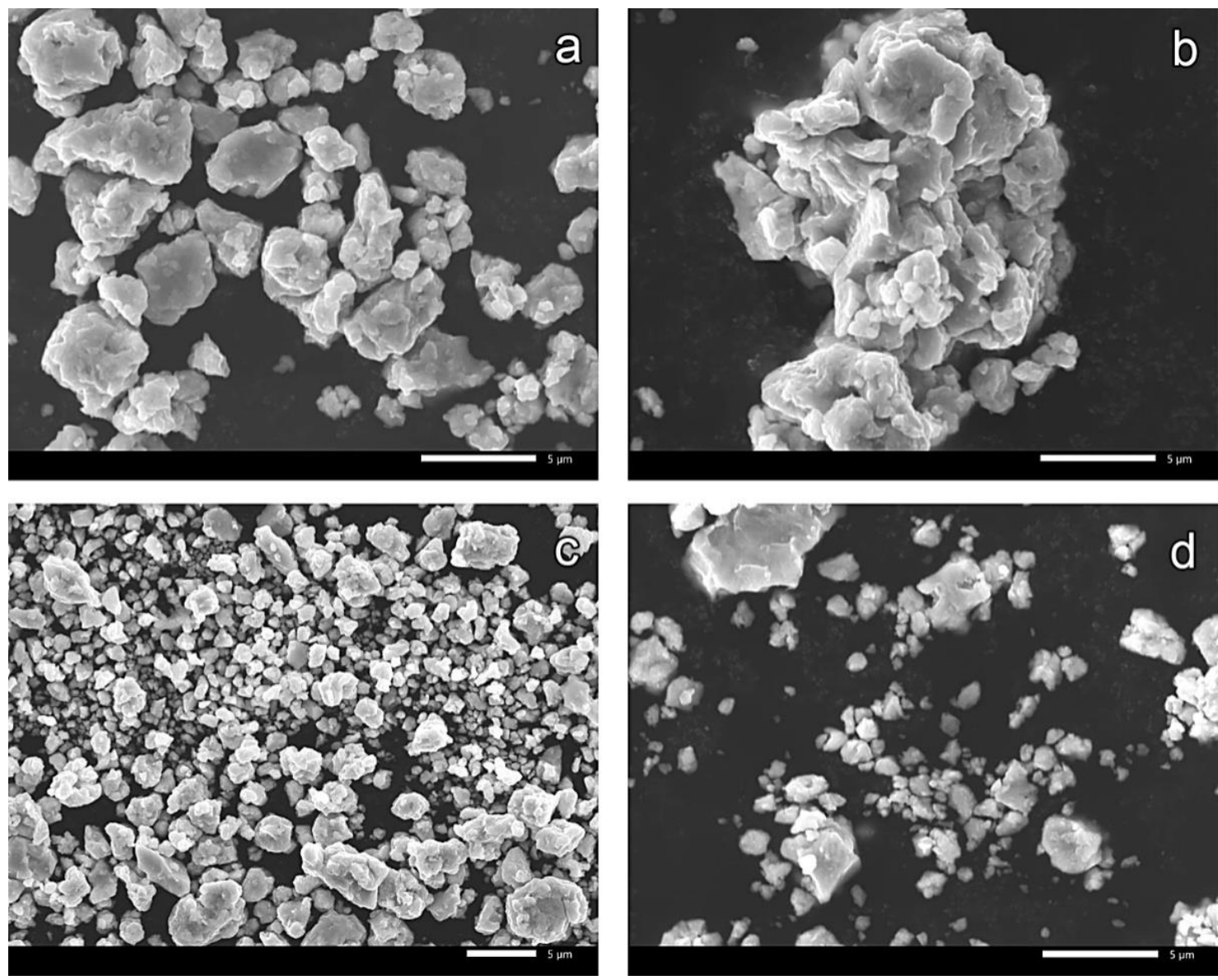

Figure 2 SEM results of the Nd-Fe-B alloy with $0.05 \% \mathrm{Cu}$ after mechanochemical synthesis in contrast of secondary electrons 



Figure $3 \mathrm{X}$-ray diffraction patterns of alloys of the Nd-Fe-B system with $\mathrm{Cu}$ additives after crystallization annealing for 15 minutes at a temperature of $600^{\circ} \mathrm{C}$

Table 2 The qualitative and quantitative phase analysis results of the $\mathrm{Nd}-\mathrm{Fe}-\mathrm{B}-\mathrm{Cu}$ samples after heat treatment at $600^{\circ} \mathrm{C}$

\begin{tabular}{|c|c|c|c|c|c|c|c|}
\hline \multirow{2}{*}{ Samples } & \multicolumn{3}{|c|}{$\begin{array}{c}\text { Mass fraction } \\
\text { (\%) }\end{array}$} & \multicolumn{2}{|c|}{$\begin{array}{c}\text { Crystallite size } \\
\text { (nm) }\end{array}$} & \multicolumn{2}{|c|}{$\begin{array}{l}\text { Lattice parameters } \\
\qquad(\mathrm{nm})\end{array}$} \\
\hline & $\mathrm{Nd}_{2} \mathrm{Fe}_{14} \mathrm{~B}$ & $\alpha-\mathrm{Fe}$ & $\mathrm{Nd}_{2} \mathrm{O}_{3}$ & $\mathrm{Nd}_{2} \mathrm{Fe}_{14} \mathrm{~B}$ & $\alpha-F e$ & $\mathrm{Nd}_{2} \mathrm{Fe}_{14} \mathrm{~B}$ & $\alpha-F e$ \\
\hline $\mathrm{Nd}_{2} \mathrm{Fe}_{14} \mathrm{~B}+0 \% \mathrm{Cu}$ & $78 \pm 3$ & $18 \pm 2$ & $4 \pm 1$ & $15 \pm 1$ & $10 \pm 1$ & $\begin{array}{l}a=0.881 \pm 0.001 \\
c=1.219 \pm 0.001\end{array}$ & $a=0.288 \pm 0.001$ \\
\hline $\mathrm{Nd}_{2} \mathrm{Fe}_{14} \mathrm{~B}+0.05 \% \mathrm{Cu}$ & $80 \pm 3$ & $15 \pm 2$ & $5 \pm 1$ & $15 \pm 1$ & $10 \pm 1$ & $\begin{array}{l}a=0.882 \pm 0.001 \\
c=1.219 \pm 0.001\end{array}$ & $a=0.288 \pm 0.001$ \\
\hline $\mathrm{Nd}_{2} \mathrm{Fe}_{14} \mathrm{~B}+0.1 \% \mathrm{Cu}$ & $81 \pm 3$ & $12 \pm 3$ & $7 \pm 1$ & $15 \pm 1$ & $10 \pm 1$ & $\begin{array}{l}a=0.881 \pm 0.001 \\
c=1.219 \pm 0.001\end{array}$ & $a=0.288 \pm 0.001$ \\
\hline $\mathrm{Nd}_{2} \mathrm{Fe}_{14} \mathrm{~B}+0.3 \% \mathrm{Cu}$ & $79 \pm 3$ & $16 \pm 3$ & $5 \pm 1$ & $16 \pm 1$ & $9 \pm 1$ & $\begin{array}{l}a=0.880 \pm 0.001 \\
c=1.219 \pm 0.001\end{array}$ & $a=0.287 \pm 0.001$ \\
\hline $\mathrm{Nd}_{2} \mathrm{Fe}_{14} \mathrm{~B}+0.4 \% \mathrm{Cu}$ & $80 \pm 3$ & $17 \pm 3$ & $3 \pm 1$ & $16 \pm 1$ & $9 \pm 1$ & $\begin{array}{l}a=0.880 \pm 0.001 \\
c=1.219 \pm 0.001\end{array}$ & $a=0.287 \pm 0.001$ \\
\hline $\mathrm{Nd}_{2} \mathrm{Fe}_{14} \mathrm{~B}+0.5 \% \mathrm{Cu}$ & $81 \pm 3$ & $16 \pm 3$ & $3 \pm 1$ & $16 \pm 1$ & $9 \pm 1$ & $\begin{array}{l}a=0.880 \pm 0.001 \\
c=1.219 \pm 0.001\end{array}$ & $a=0.287 \pm 0.001$ \\
\hline
\end{tabular}

Figure 4 presents typical hysteresis loops for samples with different $\mathrm{Cu}$ content after crystallization annealing in vacuum at $\mathrm{T}=600{ }^{\circ} \mathrm{C}$ for $15 \mathrm{~min}$. The results the magnetic properties measurements of the samples after annealing are presented in Table 3. 




Figure 4 Hysteresis loops of $\mathrm{Nd}-\mathrm{Fe}-\mathrm{B}$ samples with $\mathrm{Cu}$ after annealing at $\mathrm{T}=620^{\circ} \mathrm{C}$ for $15 \mathrm{~min}$

Table 3 Magnetic properties of Nd-Fe-B samples with $\mathrm{Cu}$ after annealing at $\mathrm{T}=620^{\circ} \mathrm{C}$ for $15 \mathrm{~min}$

\begin{tabular}{|c|c|c|c|}
\hline Sample & $\begin{array}{c}\text { Coercivity } \boldsymbol{H}_{c i} \\
(\mathbf{k A} / \mathbf{m})\end{array}$ & $\begin{array}{c}\text { Remanence } \sigma_{r} \\
\left(\mathbf{A} \cdot \mathbf{m}^{2} / \mathbf{k g}\right)\end{array}$ & $\begin{array}{c}\text { Saturation magnetization } \sigma_{s} \\
\left(\mathbf{A} \cdot \mathbf{m}^{2} / \mathbf{k g}\right)\end{array}$ \\
\hline $\mathbf{N d}_{2} \mathrm{Fe}_{14} \mathrm{~B}+\mathbf{0} \% \mathrm{Cu}$ & 166 & 44 & 120 \\
\hline $\mathbf{N d}_{2} \mathrm{Fe}_{14} \mathrm{~B}+\mathbf{0 . 0 5 \% C u}$ & 253 & 54 & 120 \\
\hline $\mathbf{N d}_{2} \mathrm{Fe}_{14} \mathrm{~B}+\mathbf{0 . 1} \% \mathrm{Cu}$ & 215 & 50 & 118 \\
\hline $\mathbf{N d}_{2} \mathrm{Fe}_{14} \mathrm{~B}+\mathbf{0 . 3} \% \mathrm{Cu}$ & 266 & 57 & 120 \\
\hline $\mathbf{N d}_{2} \mathrm{Fe}_{14} \mathrm{~B}+\mathbf{0 . 4 \%} \mathrm{Cu}$ & 376 & 67 & 126 \\
\hline $\mathbf{N d}_{2} \mathrm{Fe}_{14} \mathrm{~B}+\mathbf{0 . 5} \% \mathrm{Cu}$ & 109 & 44 & 121 \\
\hline
\end{tabular}

According to the magnetic properties measurements results, it can be concluded that with increasing annealing temperature and $\mathrm{Cu}$ content, the saturation magnetization values do not change for all samples. However, the regularity of the extreme dependence of the coercivity and the remanence is also traced for all alloys. The hysteresis properties for samples with $0 \% \mathrm{Cu}$ are small for all temperatures. With the $\mathrm{Cu}$ content increase, magnetic properties slightly increase and at the level of $0.1 \%$ there is a properties drop, which may be associated with an insufficient amount of copper to interact with the grain boundary phase. While about $20 \%$ of $\mathrm{Fe}$ is released in the alloy. A further increase in $\mathrm{Cu}$ leads to a significant increase in magnetic properties and reaches its maximum at a concentration of $0.4 \% \mathrm{Cu}$. This can be associated with the optimal amount of $\mathrm{Cu}$ necessary to create a continuous non-magnetic layer along the grain boundaries, which is necessary to obtain a highly coercive state. A further increase in Cu leads to a significant decrease in properties, which is in good agreement with published data [7-9].

Since it is not possible to detect the direct influence of $\mathrm{Cu}$ on the microstructure and magnetic properties by the structural methods used in this work, one of the other indirect methods is to study the low-temperature dependences of the magnetic properties. The temperature dependence of the hysteresis properties is well studied and it is known that with the temperature decrease, the coercivity and remanence increase. However, as a result of the presence of a spin-reorientation transition in the $\mathrm{Nd}_{2} \mathrm{Fe}_{14} \mathrm{~B}$ compound at $135 \mathrm{~K}$, below this 
temperature the hysteresis properties drop. Works [11] showed that if the dependence $\sqrt{H_{c}}$ vs $T^{2 / 3}$ down to the temperature of the spin-reorientation transition is described by a linear approximation, this indirectly indicates on the pinning mechanism in the formed non-magnetic copper layer. Figure 5 shows the temperature dependence of coercivity for the $\mathrm{Nd}-\mathrm{Fe}-\mathrm{B}$ alloy with $0.4 \% \mathrm{Cu}$, measured at temperatures from 300 to $50 \mathrm{~K}$ in a field of up to $2600 \mathrm{kA} / \mathrm{m}$.

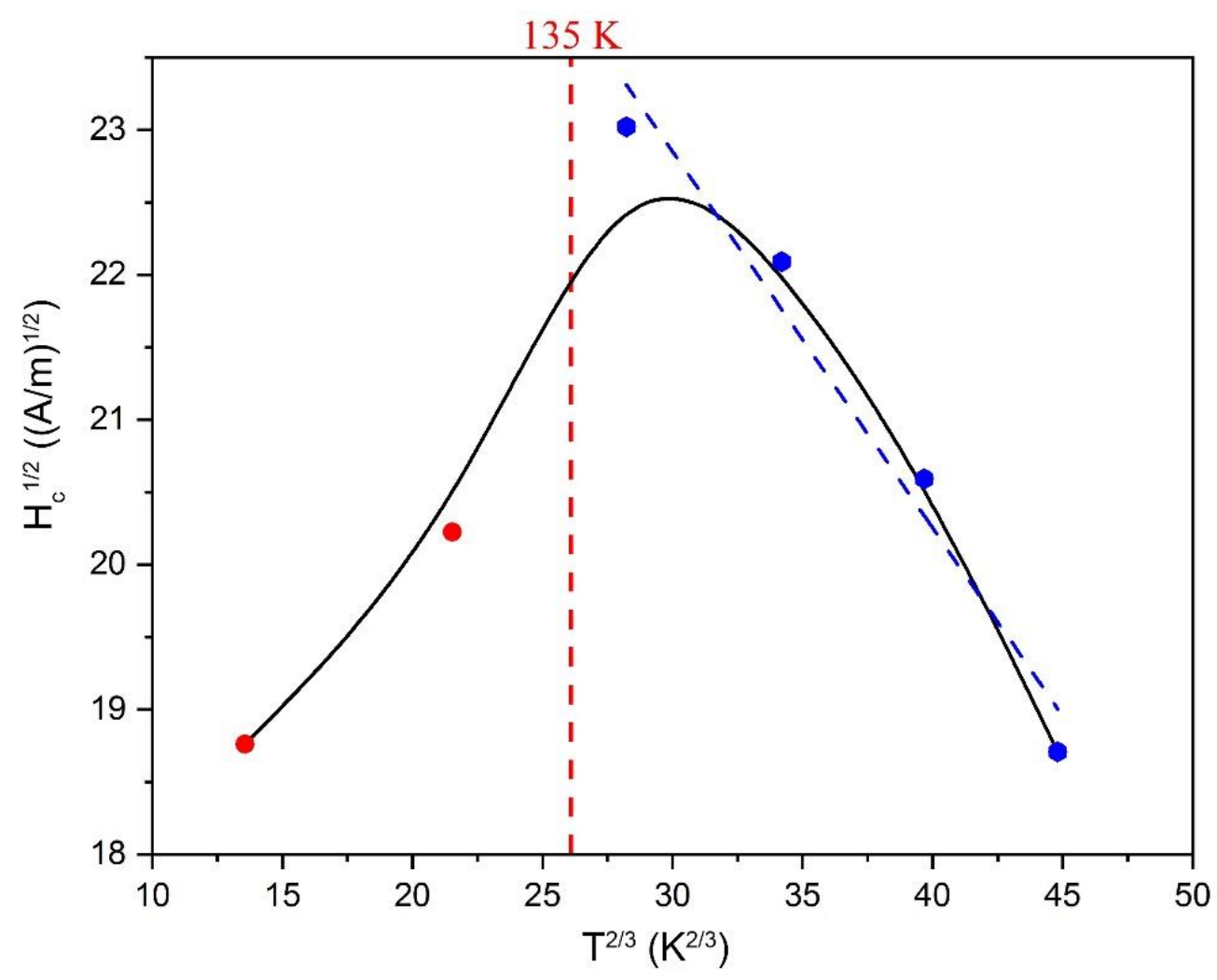

Figure 5 The temperature dependence of the coercivity in coordinates $\sqrt{H_{c}}\left(T^{\frac{2}{3}}\right)$

According to these results, it was found that down to the temperature of the spin-reorientation transition in the $\mathrm{Nd}_{2} \mathrm{Fe}_{14} \mathrm{~B}$ compound $(135 \mathrm{~K}$ ), the curve is well described by a linear approximation. This can be related to the presence of a domain walls pinning mechanism, presumably in the phases formed by the $\mathrm{Cu}$ addition.

\section{CONCLUSION}

The Nd-Fe-B alloys with $\mathrm{Cu}$ additions $(0-0.5 \%)$ were obtained by the mechanochemical synthesis method (MS). It was found that during the MS a partial decomposition of the crystalline phase $\mathrm{Nd}_{2} \mathrm{Fe}_{14} \mathrm{~B}$ into the amorphous phase $(20 \%)$ and $\alpha-\mathrm{Fe}(8 \%)$ occurs. According to SEM, the particle size was about $1 \mu \mathrm{m}$. The particles have an internal substructure.

After MS the magnetic properties of the samples have an extreme dependence for the remanence and coercivity with a maximum at $0.4 \% \mathrm{Cu}$. The change in the saturation magnetization is insignificant.

The annealing of the samples in the temperature range $560-620^{\circ} \mathrm{C}$ (for $15 \mathrm{~min}$ ) leads to crystallization of the amorphous phase and is accompanied by the coercivity and remanence increase. The maximum hysteresis properties were obtained on samples with $0.4 \% \mathrm{Cu}$ at $T=620^{\circ} \mathrm{C}: H_{c}=376 \mathrm{kA} / \mathrm{m}, \sigma_{r}=65 \mathrm{~A} \cdot \mathrm{m}^{2} / \mathrm{kg}$. In alloys with a lower $\mathrm{Cu}$ content, a decrease in hysteresis properties is observed (even compared to alloys without additions), which can be due to the $\mathrm{Nd}_{2} \mathrm{Fe}_{14} \mathrm{~B}$ phase amount decrease. While $\mathrm{Cu}$ concentrations were more than $0.4 \%$, it leads to the formation of a large amount of $\alpha-\mathrm{Fe}$. 
As a result of low-temperature magnetic measurements, it was found that down to the temperature of the spinreorientation transition, the dependence $\sqrt{H_{c}}$ vs $T^{2 / 3}$ is linear, which is probably due to the presence of a domain walls pinning mechanism, presumably in the phases formed by the $\mathrm{Cu}$ addition.

\section{ACKNOWLEDGEMENTS}

The work was supported by Russian Science Foundation, agreement № 18-72-10161.

\section{REFERENCES}

[1] DAVIES, B.E., MOTTRAM, R.S., HARRIS, I.R. Recent developments in the sintering of NdFeB. Materials Chemistry and Physics. 2001, vol. 67, pp. 272-281.

[2] MADUGUNDO, R., RAO, N.V.R., SCHÖNHÖBEL, A.M., SALAZAR, D., EL-GENDY, A.A. Recent developments in nanostructured permanent magnet materials and their processing methods. Magnetic Nanostructured Materials. 2018, vol. 1, pp. 157-198.

[3] WITHANAWASAM, L., HADJIPANAYIS, G.C., KRAUSE, R.F. Enhanced remanence in isotropic Fe-rich meltspun Nd-Fe-B ribbons. Journal of Applied Physics. 1994, vol. 75, pp. 6646-6648.

[4] SHCHETININ, I., AGGREY, P., BORDYUZHIN, I., SAVCHENKO, A., GORSHENKOV, ZHELEZNIY, M., MENUSHENKOV, V., MOGIL'NIKOV, P. Phase formation and magnetic properties of melt spun and annealed $\mathrm{Nd}-\mathrm{Fe}-\mathrm{B}$ based alloys with Ga additions. Metals. May 2019, vol. 9, iss. 5.

[5] WOODCOCK, T.G., ZHANG, Y., HRKAC, G., CIUTA, G., DEMPSEY, N.M., SCHREFL, T., GUTFLEISCH, O., GIVORD. D. Understanding the microstructure and coercivity of high performance NdFeB-based magnets. Scripta Mater. 2012, vol. 67, pp. 536-541.

[6] HRKAC, G., WOODCOCK, T.G., BUTLER, K.T., SAHARAN, L., BRYAN, M.T., SCHREFL, T., GUTFLEISCH, O. Impact of different Nd-rich crystal-phases on the coercivity of Nd-Fe-B grain ensembles. Scripta Materialia. 2014, vol. 70, pp. 35-38.

[7] RAGG, O.M., HARRIS, I.R. A study of the effects of heat treatment on the microstructures and magnetic properties of Cu-added Nd-Fe-B type sintered magnets. Journal of Alloys and Compounds. 1994, vol. 209, pp. 125-133.

[8] YANG, Y., SI, H., YANG, H., ZHANG, L., HUANG, D., CHEN, B., HAN, B. Re-exchange of Fe and Cu at the interface in sintered $\mathrm{Nd}-\mathrm{Fe}-\mathrm{B}$ magnets: A method to eliminate Fe precipitation at grain boundaries. Physics Letters A. 2018, vol. 382, pp. 135-138.

[9] TAE-HOON KIM, SEONG-RAE LEE, HYO-JUN KIM, TAE-SUK JANG. Dependence of magnetic, phasetransformation and microstructural characteristic on the Cu content of Nd-Fe-B sintered magnet. Acta Materialia. 2014, vol. 66, pp. 12-21.

[10] SAVCHENKO, A.G., MEDVEDEVA, T.M., SHCHETININ, I.V., MENUSHENKOV, V.P., GORSHENKOV, M.V., SAVCHENKO, E.S., BORDYUZHIN, I.G. Phase-structural state diagrams and hysteresis properties of rapidly solidified alloy Nd10.4Zr4.0Fe75.1Co4.1B6.4 after heat treatment. J. Alloy. Compd. 2017, vol. 707, pp. 205-209.

[11] GAUNT, P. Ferromagnetic domain wall pinning by a random array of inhomogeneities. Philosophical Magazine $B$. 1983, vol. 48, no. 3, pp. 261-276. 